\title{
PENGARUH PENILAIAN DAN MENTORING TERHADAP PENINGKATAN KINERJA KARYAWAN RUMAH SAKIT ISLAM NASRUL UMMAH
}

\author{
Moch. Bayu Hindarto \\ Universitas Negeri Surabaya \\ bayu.17080574077@mhs.unesa.ac.id
}

\begin{abstract}
Employee performance is very influential on the service of a hospital. This study aims to determine the effect of performance appraisal and mentoring on employee performance at The Islamic Hospital Nasrul Ummah of Lamongan. The population of this study were all hospital employees from health workers, pharmacists and other administrative divisions. This study used a sample of 76 (seventy-six) people with a random sampling method. Data analysis used multiple linear regression with SPSS Statistics 26 for Mac from IBM. The effect of performance appraisal and mentoring is positively significant. Nasrul Ummah Islamic Hospital must continue to performance appraisal and mentoring its employees to maintain their performance well to attract people to choose Nasrul Ummah Islamic Hospital over another hospital.
\end{abstract}

Keywords: employee performance; mentoring; performance appraisal.

\section{PENDAHULUAN}

Perkembangan ilmu pengetahuan menuntut Rumah Sakit untuk adaptif. Di zaman modern, persaingan diantara Rumah Sakit semakin kompetitif, sehingga sebuah organisasi harus mengoptimalkan sumber daya yang dimiliki organisasi terutama sumber daya manusia (Wilandari et al., 2021). Pengoptimalan tersebut bisa dilaksanakan oleh semua lembaga yang bergerak dalam bidang penyedia barang ataupun jasa karena sumber daya manusia sendiri memiliki fungsi yang strategis disemua lini lembaga tersebut. Semakin meningkatnya peran sumber daya manusia yang yang berada pada organisasi, maka akan meningkatkan kompetensi dan kinerja organisasi (Daft, 2010). Tipung (2018) menyatakan bahwa kinerja karyawan yang optimal dapat dicapai dengan memerhatikan kualitas manajemen sumber daya manusia dengan meningkatkan hubungan kerja di antara karyawan dan sumber daya lainnya agar dapat menghasilkan kinerja karyawan yang optimal.

Robbins \& Decenzo (2004) menyatakan Human Resource Management (HRM) merupakan kegiatan yang bersumber dari tugas-tugas seperti menarik, mengembangkan, memotivasi dan memertahankan sumber daya manusia. Kemudian menurut Schuler et al. (1992), HRM adalah pengakuan vital karyawan sebagai human resource management yang penting agar mendapatkan sebuah target yang diberikan organisasi dan pemanfaatan mereka dalam fungsi dan tugas yang secara efektif dan adil guna kepentingan individu, organisasi, dan masyarakat. Rivai (2009) berpendapat bahwa kinerja merupakan perbuatan asli yang dilakukan banyak orang sebagai sebuah keunggulan kerja yang diperoleh oleh karyawan sesuai dengan peranya di dalam Rumah Sakit. HRM menjadi penting dan dibutuhkan guna mengoptimalkan hasil dari sumber daya manusia agar mampu berkontribusi secara maksimal untuk mencapai tujuan Rumah Sakit (Alwi, 2012). Mengukur kinerja Rumah Sakit menggunakan perspektif ekonomi sangat akurat, tetapi yang menjadi dasar penggerak dari ekonomi merupakan sumber daya manusia menggunakan semua pengetahuan, ide, dan inovasi yang dimiliki (Mayo, 2000).

Kompetensi yang dimiliki oleh tenaga kesehatan adalah kunci dari suatu rumah sakit (Kemenkes RI, 2020). Menurut BPS, Pulau Jawa memiliki persentase sebesar 56,1\% dari total penduduk Indonesia dan Jawa Timur berperan sebanyak $15 \%$ yang merupakan propinsi dengan penduduk tertinggi kedua. Data selengkapnya dapat dilihat di Gambar 1 (BPS, 2021).

Jawa Timur juga memiliki jumlah Rumah Sakit terbanyak di Indonesia dengan total persentase sebesar 13,2\%. Data selengkapnya dapat dilihat di tabel 1. Kabupaten Lamongan memiliki delapan Rumah Sakit terakreditasi. Rumah Sakit Islam Nashrul Ummah (RSI. NU) adalah salah satu dari sekian rumah 
Moch. Bayu Hindarto. Pengaruh Penilaian dan Mentoring terhadap Peningkatan Kinerja Karyawan Rumah Sakit Islam Nasrul Ummah

sakit terakreditasi yang berada di Kabupaten Lamongan dengan persentase tenaga medis atau karyawan sejumlah 8,27\% dari total tenaga medis atau karyawan yang ada di Kabupaten Lamongan (Kemenkes RI, 2021). Temuan tersebut menjadikan RSI.NU sebagai rumah sakit yang layak untuk dilakukan penelitian terkait kinerja karyawan karena pasti ada peran kinerja karyawan yang menjadikan RSI NU menjadi rumah sakit terbesar di Kabupaten Lamongan.

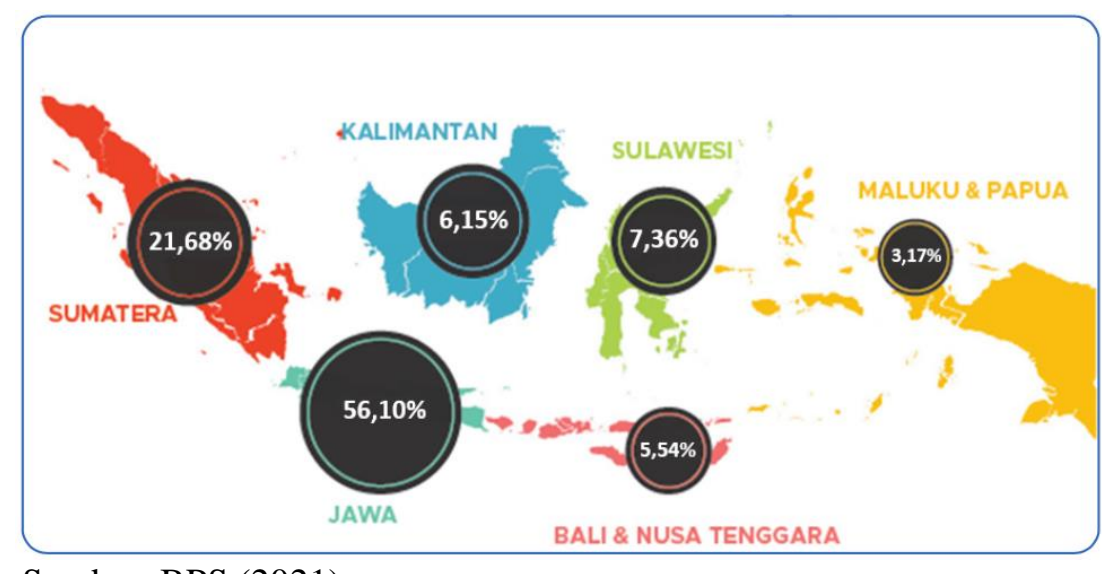

Sumber: BPS (2021)

Gambar 1. SEBARAN DATA PENDUDUK

Tabel 1.

PERSENTASE JUMLAH RUMAH SAKIT PULAU JAWA

\begin{tabular}{lr}
\hline RS Propinsi & Persentase \\
\hline Jawa Timur & 13,2 \\
Jawa Barat & 12,7 \\
Jawa Tengah & 10,7 \\
DKI & 6,5 \\
Banten & 4,1 \\
\hline Sumber: Kemenkes RI (2021)
\end{tabular}

Salah satu bagian dari HRM adalah penilaian di mana Robbins \& Decenzo (2004) berpendapat penilaian kerja (performance appraisal) adalah kegiatan di mana organisasi melaksanakan evaluasi dan penilaian terhadap kinerja. Alewine (1999) berpendapat penilaian kinerja adalah untuk menciptakan karyawan melihat diri mereka sendiri apa adanya, mengetahui keperluan perbaikan kinerja dan untuk mengambil posisi dalam merancang perbaikan kinerja.

Penilaian prestasi kerja menurut Wilandari et al. (2021) adalah kegiatan perhitungan prestasi kerja karyawan sesuai dengan ketentuan yang berlaku, dengan cara perbandingan target (hasil kerjanya) dengan syarat deskripsi pekerjaan yaitu standar kerja yang sudah dibuat selama masa waktu tertentu. Standar kerja dapat menggunakan kualitatif ataupun kuantitatif. Menurut Dessler (2013), performance appraisal suatu kegiatan penilaian prestasi kinerja karyawan dikerjakan oleh pimpinan Rumah Sakit dengan sistematis yang didasarkan oleh pekerjaan yang diberikan untuknya.

Siswanto (1996) mengutarakan bahwa monitoring atau pengawasan adalah suatu kegiatan yang sistematik guna evaluasi apakah kegiatan-kegiatan organisasi yang dikerjakan sama dengan rencana yang sudah dibuat dan jika belum dikerjakan diagnosa faktor penyebabnya untuk dilakukan sebuah perbaikan. Anjaningrum \& Sapoetra (2018) berpendapat bahwa monitoring adalah seseorang yang menerjemahkan politik dan aturan-aturan yang bekerja pada suatu kelas yang mana harus mengawasi secara pribadi terhadap pekerjaan yang diberikan kepada unit-unit kecil untuk menemukan performance yang tepat.

Temuan fenomena gap berupa link and match data BPS dan Kemenkes RI serta hasil wawancara dengan pihak RSI NU yang menjelaskan bahwa penilaian dan mentoring yang sudah berjalan selama ini 
menunjukkan hasil yang baik dilihat dari kinerja karyawan yang ada. Agustin (2019) dan Evaline \& Bullah (2017) menemukan bahwa tidak terdapat pengaruh signifikan antara variabel penilaian terhadap kinerja. Akan tetapi, Tipung (2018) menyatakan mentoring memiliki dampak yang positif namun tidak signifikan terhadap kinerja. Atas temuan tersebut, menjadi potensi untuk dilakukan penelitian kembali. Penelitian ini memiliki tujuan dalam mengetahui pengaruh penilaian dan mentoring terhadap kinerja karyawan di RSI Nasrul Ummah Lamongan.

\section{KAJIAN PUSTAKA DAN PENGEMBANGAN HIPOTESIS}

\section{Kinerja Karyawan}

Al-Jedaia \& Mehrez (2020) menyatakan kinerja merupakan hasil kerja atau prestasi kerja. Artinya, kinerja merupakan hasil pekerjaan organisasi yang dikerjakan karyawan sesuai pedoman (manual), arahan pimpinan, kompetensi dan kemampuan mengembangkan nalar dalam bekerja. (Daoanis, 2012) mengutarakan kinerja atau performance merupakan bentuk tingkat pencapaian pelaksanaan kegiatan atau kebijakan untuk mewujudkan sasaran, tujuan, visi, dan misi organisasi melalui perencanaan strategis organisasi. Marta \& Wardoyo (2016) menyatakan bahwa kinerja mengacu kepada kadar pencapaian tugas-tugas yang membentuk sebuah pekerjaan karyawan, kinerja merefleksikan seberapa baik seorang karyawan memenuhi persyaratan sebuah pekerjaan. Qosim, Seputra, \& Minarsih (2018) menyatakan indikator dari kinerja karyawan antara lain kualitas, kuantitas, ketepatan waktu, efektivitas, dan kemandirian.

\section{Penilaian}

Dessler (2013) mendeskripsikan penilaian sebagai evaluasi kinerja karyawan secara relatif terhadap standar kinerjanya. Penilaian yang efektif mengharuskan supervisor menetapkan standar kinerja. Pendapat lain dikemukakan oleh Mathis \& Jackson (2006) bahwa proses evaluasi kinerja karyawan dalam melakukan pekerjaan dibandingkan dengan pemberian standardisasi kinerja dan memberikan informasi tersebut kepada karyawan. Penilaian kinerja mencerminkan kebutuhan pemberi kerja untuk pengukuran kinerja pekerja yang komprehensif (Heywood, Jirjahn, \& Struewing, 2017). Evaluasi kinerja pekerja untuk mengontrol penyebaran mereka dan mengelola proses HRM tertentu yang sesuai (Bayo-Moriones et al., 2021). Berdasarkan pendapat di atas, penilaian kinerja merupakan evaluasi yang dilakukan oleh pimpinan terhadap karyawan di suatu bidang tertentu yang sesuai dengan standar kinerja yang ada. Warokka, Gallato, \& Morothy (2012) menyatakan indikator dari penilaian antara lain sistem penilaian, proses implementasi penilaian, dan proses output penilaian.

\section{Mentoring}

Allen et al. (2009) dan Jones (2012) menyatakan bahwa mentoring merupakan metode penting untuk mentransfer pengetahuan diam-diam. Menurut Simmonds \& Dick (2018) mentoring merupakan proses umpan balik dan dinamis antar individu dalam membangun hubungan dengan individu yang terampil, memiliki banyak informasi, pengetahuan dan fokus dalam pengembangan profesionalitas dan kepribadiam. Mentoring menunjukkan pendampingan memperkaya sumber daya psikologis dalam memberdayakan kemandirian untuk meningkatkan kinerja juga dapat membangun harapan anak didik melalui pengembangan jalur yang diperlukan (Carter et al., 2019). Castro \& Scandura (2004) menyatakan indikator dari mentoring antara lain pembelajaran pribadi, kepuasan kerja, nilai kesamaan, dan dukungan kerja.

\section{Hubungan antar variabel}

Penilaian berbanding lurus terhadap kinerja karyawan (Dessler, 2013). Hasil positif dan signifikan ditemui pada pengaruh penilaian terhadap kinerja karyawan (Al-Jedaia \& Mehrez, 2020; Khan, Khan, \& Khan, 2017; Setiawati \& Ariani, 2019; Wilandari et al., 2021). Namun ada beberapa penelitian yang didapatkan hasil berupa penilaian tidak berpengaruh terhadap kinerja karyawan atau juga disebut non signifikan, hasil non signifikan ditemui pada penelitian Agustin (2019) dan Evaline \& Bullah (2017). Maka, hipotesis riset ini yang pertama adalah sebagai berikut.

H1: Penilaian berpengaruh positif terhadap kinerja karyawan. 
Moch. Bayu Hindarto. Pengaruh Penilaian dan Mentoring terhadap Peningkatan Kinerja Karyawan Rumah Sakit Islam Nasrul Ummah

Mentoring berbanding lurus terhadap kinerja karyawan (Allen et al., 2009 dan Jones, 2012). Hasil positif dan signifikan ditemui pada pengaruh mentoring terhadap kinerja karyawan (Anjaningrum \& Sapoetra, 2018; Chatterjee, Dey, \& Chaturvedi, 2021; Lee \& Lee, 2018; Mundia \& Iravo, 2014; Neupane, 2015; Ofobruku \& Nwakoby, 2015; Oladimeji \& Sowemimo, 2020). Namun ada penelitian yang didapatkan hasil berupa mentoring tidak berpengaruh terhadap kinerja karyawan atau juga disebut non signifikan, hasil non signifikan ditemui pada penelitian Tipung (2018).

H2: Mentoring berpengaruh positif terhadap kinerja karyawan.

Gambar 1 mengilustrasikan pengaruh antar variabel secara keseluruhan.

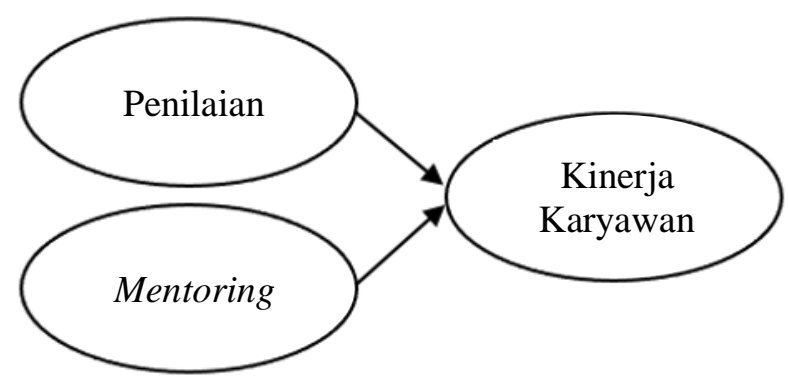

Gambar 1. MODEL PENELITIAN

\section{METODE PENELITIAN}

Riset ini berjenis kausal kuantitatif untuk mencari keterkaitan antar variabel. Riset menggunakan pendekatan kuantitatif. Riset ini dilakukan pada RSI NU. Multiple linear regression digunakan sebagai teknik analisis dalam riset ini yang bertujuan menguji pengaruh antara dua atau lebih variabel bebas yang memengaruhi variabel terikat. Penilaian (X1) dan mentoring (X2) sebagai variabel bebas yang berpengaruh terhadap kinerja karyawan (Y).

Metode penentuan sampel dalam penelitian ini menggunakan random sampling. Semua tenaga kerja (Tenaga Kesehatan, Apoteker, dan Administrasi) RSI NU adalah populasi dengan ukuran sampel yang ditetapkan setelah menggunakan rumus $\mathrm{n}=\mathrm{N} /\left(1+\left(\mathrm{N} \mathrm{x} \mathrm{e}^{2}\right)\right)$ dan ditemukan hasil yang berjumlah 76 sampel. Pengumpulan data sampel dilaksanakan dengan cara memberikan kuisioner pada tenaga kerja RSI NU. dengan menggunakan skala Likert dalam tolok ukur instrumen penelitian. Data diolah menggunakan aplikasi IBM SPSS Statistics 26.

\section{HASIL DAN PEMBAHASAN}

\section{Hasil Uji Statistik}

Sebelum menguji regresi linier berganda dalam mengetahui pengaruh variabel dependen terhadap variabel independen, pengujian instrumen meliputi validitas serta reliabilitas terlebih dahulu dilaksanakan. Setelahnya melakukan uji asumsi klasik normalitas, heteroskedasitas, dan multikolinieritas sebagai syarat sebelum menguji pengaruh.

\section{Uji Validitas}

Berdasarkan hasil uji validitas menggunakan alat spss dalam penelitian ini menunjukkan hasil bahwa setiap indikator memiliki nilai $r$ hitung $>r$ tabel yaitu di atas dari nilai 0,225. Maka, setiap instrumen dikatakan valid dalam menghitung jawaban setiap responden dari obyek penelitian.

\section{Uji Reliabilitas}

Hasil uji reliabilitas dalam penelitian dikatakan reliable apabila nilai cronbach's alpha sebesar $>0,7$ (Ghozali, 2018). Dalam penelitian ini nilai cronbach's alpha dari setiap indikator sebesar 0,93, yang artinya setiap variabel oleh penelitian ini dikatakan reliabel menjadi instrumen dalam medapatkan data sampel dari obyek penelitian. 


\section{Uji Normalitas}

Hasil tabel 2 menggunakan uji Kolmogorov-smirnov terhadap setiap variabel memperlihatkan nilai sig. $>0,05$. Nilai uji memperlihatkan sampel penelitian berdistribusi normal (Ghozali, 2018).

\section{Tabel 1.}

\section{UJI NORMALITAS, HETEROSKEDASITAS, DAN MULTIKOLINIERITAS}

\begin{tabular}{lcccc}
\hline \multicolumn{1}{c}{ Model } & K-S (Sig.) & Tolerenace & VIF & Gletser (Sig.) \\
\hline Kinerja & 0,82 & & & - \\
Penilaian & 0,91 & 0,999 & 1,001 & 0,916 \\
Mentoring & 0,91 & & & 0,321 \\
\hline
\end{tabular}

Sumber: Data diolah (2021)

\section{Uji Heteroskedastisitas}

Hasil tabel 2 menggunakan uji gletser kepada setiap variabel independen menghasilkan nilai sig. > 0,05. Nilai uji gletser memperlihatkan bahwa sampel tidak mempunyai gejala heteroskedasitas (Ghozali, 2018).

\section{Uji Multikolinieritas}

Dari nilai tolerance dan VIF tabel 2 memperlihatkan setiap variabel mempunyai nilai tolerance 0,999 $>0,1$ dan nilai VIF $1,001<10$. Hasil uji statistic, data sampel penelitian tersebut tidak mempunyai gejala multikolinieritas (Ghozali, 2018).

\section{Uji Regresi Linier Berganda}

Tabel 3 memperlihatkan nilai uji regresi linier berganda dengan persamaan regresi (1). Didapati nilai konstanta 22,455 satuan dengan maksud variabel kinerja karyawan memiliki nilai sebesar 22,455 satuan apabila semua variabel bernilai konstan. Koefisien regresi penilaian 0,68 dengan arti setiap kenaikan variabel penilaian sebanyak satu satuan, variabel kinerja karyawan dapat bertambah 0,68 satuan. Koefisien regresi mentoring sebesar 0,139 artinya setiap peningkatan satu satuan variabel mentoring, kinerja karyawan dapat meningkat sebesar 0,139 satuan.

$Y=22,455+0,68 P+0,139 M$

\section{Tabel 2.}

HASIL UJI REGRESI LINIER BERGANDA, UJI F, UJI T, DAN DETERMINASI

\begin{tabular}{lccc}
\hline \multicolumn{1}{c}{ Model } & Koefisien & $\mathrm{t}$ & Sig. \\
\hline (Constant) & 22,455 & 5,599 & 0,000 \\
Penilaian & 0,68 & 7,82 & 0,000 \\
Mentoring & 0,139 & 1,595 & 0,012 \\
F Test & 31,467 & - & 0,000 \\
Adj. R Squared & & & 0,448 \\
\hline
\end{tabular}

Sumber: Data diolah (2021)

\section{Uji Statistik F}

Tabel 3 memerlihatkan angka F hitung 31,467 serta nilai probabilitas 0,000. Maka, ke semua variabel yang memengaruhi penilaian kinerja secara simultan terbukti berpengaruh (Ghozali, 2018).

\section{Uji Statistik t}

Nilai t hitung variabel penilaian 7,82 dan (sig) 0,000 < 0,05. Maka, bisa dinyatakan menerima H0 dan tolak H1. Penilaian terbukti signifikan dengan arah pengaruh positif terhadap kinerja karyawan. Kemudian angka t hitung variabel mentoring sebesar 1,595 dengan angka (sig.) 0,012<0,05 yang dapat dinyatakan terima H0 dan tolak H1 (Ghozali, 2018). Mentoring terbukti signifikan dengan arah pengaruh positif terhadap penilaian kinerja. 
Moch. Bayu Hindarto. Pengaruh Penilaian dan Mentoring terhadap Peningkatan Kinerja Karyawan Rumah Sakit Islam Nasrul Ummah

\section{Uji Determinasi}

Nilai Adj. $R$ Square 0,448 atau 44,8\%. Variabel independen penelitian ini memerlihatkan sebanyak $44,8 \%$ variabel dependen, sedangkan yang lainnya 55,2\% diperoleh variabel independen di luar model regresi (Ghozali, 2018).

\section{Pengaruh Penilaian terhadap Kinerja Karyawan}

Kinerja karyawan terbukti dipengaruhi oleh penilaian. Nilai sig. penilaian yang positif signifikan menunjukkan adanya pengaruh bagaimana cara RSI NU melakukan penilaian terhadap karyawan yang menyebabkan kinerja karyawan mereka menjadi salah satu terbaik di Lamongan. Nilai uji t yang positif dan nilai mean yang mendekati maksimum cenderung menginformasikan bahwa Rumah Sakit telah melakukan penilaian secara efektif sehingga penilaian terbukti memengaruhi cara karyawan melakukan tugas dan tanggung jawabnya.

Hasil penelitian ini yang berhasil membuktikan bahwa pengaruh positif dan juga signifikan pada penilaian kepada kinerja karyawan sejalan dengan penelitian yang dilaksanakan oleh Dessler (2013). Selain itu, hasil serupa juga didapat oleh Al-Jedaia \& Mehrez (2020), Khan et al. (2017), Setiawati \& Ariani, 2019, dan Wilandari et al., 2021).

Proses penilaian kinerja yang dilaksanakan oleh RSI NU memiliki sebuah standar dan indikator yang telah ditetapkan oleh bagian HRD dengan pertimbangan untuk mencapai tujuan RSI NU dan dalam rangka pelaksanaan peraturan perundangan-undangan. Tidak hanya berhenti pada pelaksanaan, hasil yang didapatkan dari proses penilaian kinerja dianalisis untuk diambil Langkah selanjutnya. Bagi karyawan yang memiliki hasil kurang baik, RSI akan memberikan sebuah konsekuensi dengan memberhentikan karyawan tersebut. Apabila didapati hasil yang baik, maka karyawan tersebut akan dapat bertahan. Proses penilaian dilaksanakan tiap bulan yang kemudian diakumulasikan dalam satu tahun untuk diambil keputusan terhadap karyawan yang bersangkutan. Proses penilaian dilaksanakan langsung oleh kepala ruangan atau supervisor. Hasil temuan di lapangan memperlihatkan banyak karyawan yang disiplin dalam bekerja dan juga pelayanan yang mereka berikan sebaik mungkin. Para karyawan sadar bahwa pekerjaan yang mereka laksanakan di nilai oleh kepala ruangan mereka dan jika kinerja mereka tidak sesuai standar yang sudah ditetapkan, mereka dapat diberhentikan dari pekerjaan.

\section{Pengaruh Mentoring terhadap Kinerja Karyawan}

Kinerja karyawan terbukti dipengaruhi oleh Mentoring. Nilai sig. mentoring yang positif signifikan memerlihatkan pengaruh seperti apa karyawan merasa terdampingi juga terdorong dalam melakukan tugas dan tanggung jawab dalam pekerjaan yang mereka laksanakan. Nilai uji t yang positif dan nilai mean sebesar yang mendekati nilai maksimum menginformasikan bahwa Rumah Sakit telah berhasil menciptakan cara mentoring yang efektif dan memengaruhi kinerja karyawan.

Penelitian ini yang berhasil menunjukkan bahwa mentoring mempunyai pengaruh signifikan dan positif sejalan dengan penelitian Anjaningrum \& Sapoetra (2018). Selain itu, hasil serupa juga ditemui pada hasil penelitian Chatterjee, Dey, \& Chaturvedi, (2021), Lee \& Lee (2018), Mundia \&Iravo (2014), Neupane (2015), Ofobruku \& Nwakoby, (2015), serta Oladimeji \& Sowemimo (2020).

Proses mentoring di RSI NU dilaksanakan antara mentor yakni Kepala ruangan kepada mentee atau karyawan yang hendak dikembangkan kemampuan dan pengetahuannya. Dengan sebuah mentoring, mentee mendapatkan peningkatan dan pengembangan kemampuan dan pengetahuan dalam melaksanakan tugas dan tanggung jawabnya sebagai karyawan. Standar peningkatan kemampuan dan pengetahuan yang ditetapkan oleh RSI NU telah dirancang oleh bagian HRD untuk mencapai tujuan dan meningkatkan kinerja RSI NU secara umum. Proses mentoring dilaksanakan dengan memantau kinerja setiap hari dengan melakukan cross-check dengan standar. Mentor kemudian memberikan feedback lisan dan tindakan yang perlu dilakukan untuk meningkatkan potensi yang masing dibawah standar yang ditetapkan. Hasil observasi penelitian memperlihatkan bahwa para kepala ruangan sering berkomunikasi kepada karyawan terkait pekerjaan yang mereka laksanakan dan menjelaskan bagaimana seharusnya karyawan dalam melaksanakan pekerjaanya. 


\section{KESIMPULAN}

Penelitian ini menghasilkan kesimpulan bahwa penilaian dan mentoring memiliki pengaruh positif signifikan terhadap kinerja RSI NU. Penilaian memegang peranan bagaimana Rumah Sakit melakukan kontrol atas kinerja atau penilaian untuk menjaga mutu dapat memengaruhi kinerja karyawan RSI NU. Variabel mentoring yang diimplementasikan dalam RSI NU berupa pendampingan, dorongan, dan upaya lain dalam memberikan dukungan terhadap karyawan RSI NU dalam mengerjakan tugas serta tanggung jawabnya mampu memberikan dampak terhadap kinerja karyawan RSI NU. Penelitian ini juga dapat menjelaskan bahwa penilaian dan mentoring yang sudah dilaksanakan oleh pihak RSI NU memperoleh hasil yang positif berupa peningkatan kinerja karyawan yang dimiliki.

Penelitian ini memberikan beberapa saran dari hasil analisis dan pengamatan yang sudah dilaksanakan supaya hendaknya membentuk sebuah tim tersendiri untuk melaksanakan penilaian dan mentoring ketika supervisor atau kepala ruangan sedang tidak melaksanakan pengawasan. Hal tersebut bertujuan untuk pelaksanaan dari penilaian dan mentoring tersebut lebih objektif Ketika supervisor atau kepala ruangan berhalangan hadir. Standar yang telah ditetapkan dalam proses penilaian dan mentoring perlu ditingkatkan kembali dan juga dievaluasi tiap periode agar kinerja yang dimiliki oleh karyawan tidak mengalami penurunan yang dapat berdampak kepada pelayanan dari pihak RSI NU

Hasil riset disini diharapkan memiliki manfaat bagi RSI NU agar dapat mengetahui langkah selanjutnya yang dapat ditempuh guna meningkatkan kinerja karyawan mereka, sehingga pelayanan yang diberikan kepada pasien lebih memuaskan. Untuk penelitian selanjutnya diharapkan menggunakan variabel lainnya seperti hal nya employee well-being, job satisfaction, serta demografi dapat di jadikan pertimbangan untuk penelitian dengan objek yang serupa maupun berbeda.

\section{DAFTAR PUSTAKA}

Agustin, T. (2019). Pengaruh Penilaian Kinerja Terhadap Kinerja Pegawai Melalui Pengembangan Karir Pegawai Pada PT. Bank Pembangunan Daerah Kalimantan Barat Cabang Sekadadu. Equator Journal of Management and Entrepreneurship, 7(1), 1-19. Diambil dari https://jurnal.untan.ac.id/index.php/jmdb/article/view/28448

Al-Jedaia, Y., \& Mehrez, A. (2020). The effect of performance appraisal on job performance in governmental sector: The mediating role of motivation. Management Science Letters, 10(9), 2077-2088. https://doi.org/10.5267/j.msl.2020.2.003

Alewine, T. (1999). Penilaian Kinerja dan Standar Kinerja. Edisi keempat. Jakarta: Elex Media Computindo.

Allen, T., Smith, M., Mael, F., \& Gavan, O. (2009). Organization-Level Mentoring and Organizational Performance Within Substance Abuse Centers. Journal of Management, 35(5), 1113-1128.

Alwi, S. (2012). Manajemen Sumber Daya Manusia Strategi Keunggulan Kompetitif. Edisi pertama. Yogyakarta: BPFE.

Anjaningrum, W. D., \& Sapoetra, Y. A. (2018). Pengaruh Entrepreneurship, Business Coaching, Mentoring, dan Komunitas Kreatif Terhadap Kinerja Industri Kreatif (Studi pada Industri Kreatif yang Tergabung dalam Malang Creative Fusion). Jurnal Ilmiah Bisnis dan Ekonomi STIE Asia, 12(1), 83-92. Diambil dari http://lp3m.asia.ac.id/wp-content/uploads/2018/04/12.-JURNALWIDIYA-VOL-12-NO-1-B2018.pdf

Bayo-Moriones, A., Galdon-Sanchez, J. E., \& Martinez-de-Morentin, S. (2021). Business strategy, performance appraisal and organizational results. Personnel Review, 50(2), 515-534. https://doi.org/10.1108/PR-09-2019-0498 
Moch. Bayu Hindarto. Pengaruh Penilaian dan Mentoring terhadap Peningkatan Kinerja Karyawan Rumah Sakit Islam Nasrul Ummah

BPS. (2021). Hasil Sensus Penduduk 2020. Diambil dari https://www.bps.go.id/pressrelease/2021/01/21/1854/hasil-sensus-penduduk-2020.html (Diakses 15/06/2021)

Carter, J. W., \& Youssef-Morgan, C. M. (2019). The positive psychology of mentoring: A longitudinal analysis of psychological capital development and performance in a formal mentoring program. Human Resource Development Quarterly, 30(3), 383-405. https://doi.org/10.1002/hrdq.21348

Castro, S. L., \& Scandura, T. A. (2004). The tale of two measures: Evaluation and comparison of Scandura's (1992) and Ragins and McFarlin's (1990) mentoring measures. Paper presented at the Southern Management Association Meeting, San Antonio, TX. 1-39

Chatterjee, S., Dey, A. K., \& Chaturvedi, H. (2021). Effect of Mentoring on Job Performance among Indian Millennials: A Quantitative Study. International Journal of Evidence Based Coaching and Mentoring, 19(1), 90-104. https://doi.org/10.24384/nq43-ar60

Daft, R. L. (2010). Management (9 ed.). Mason: Cengage Learning.

Daoanis, L. (2012). Performance Appraisal System: Its Implication to Employee Performance. Journal of Resource Development and Management, 2(3), 55-62.

Dessler, G. (2013). Manajemen Sumber Daya Manusia. Edisi kedua. Jakarta: Prenhallindo.

Evaline, H., \& Bula, D. (2017). Performance Appraisal Systems and Employee Performance in Commercial Banks in Nairobi City County, Kenya. International Journal of Current Aspects in Human Resource Management, 114-125.

Ghozali, I. (2018). Aplikasi Analisis Multivariete SPSS 25. Edisi kesembilan. Semarang: Universitas DIponegoro.

Heywood, J. S., Jirjahn, U., \& Struewing, C. (2017). Locus of control and performance appraisal. Journal of Economic Behavior and Organization, 142, 205-225. https://doi.org/10.1016/j.jebo.2017.06.011

Jones, J. (2012). An Analysis of Learning Outcomes Within Formal Mentoring Relationships. International Journal of Evidence Based Coaching \& Mentoring, 10(1), 57-72.

Kemenkes RI. (2021). Data RS Online. Diambil dari http://sirs.yankes.kemkes.go.id/klinikonline/data_list.php?goto=6 (Diakses 15/06/2021)

Kemenkes RI. (2021). Menkes SDM Berkualitas Jadi Kunci Pelayanan Prima di Rumah Sakit. Diambil dari https://sehatnegeriku.kemkes.go.id/baca/rilis-media/20210414/3437530/menkes-sdmberkualitas-jadi-kunci-pelayanan-kesehatan-prima-di-rumah-sakit/ (Diakses 15/06/2021)

Khan, Z., Khan, A. S., \& Khan, I. (2017). Impact of Performance Appraisal on Employee's Performance Including the Moderating Role of Motivation: A Survey of Commercial Banks in Dera Ismail Khan, Khyber Pakhtunkhwa, Pakistan. Universal Journal of Industrial and Business Management, 5(1), 1-9. https://doi.org/10.13189/ujibm.2017.050101

Lee, Y., \& Lee, J. Y. (2018). A multilevel analysis of individual and organizational factors that influence the relationship between career development and job-performance improvement. European Journal of Training and Development, 42(5-6), 286-304. https://doi.org/10.1108/EJTD-112017-0097

Marta, J. D., \& Wijayati, D. T. (2018). Pengaruh Budaya Organisasi dan Komunikasi Organisasi 
terhadap Kinerja Karyawan PT. X. BISMA (Bisnis dan Manajemen), 8(2), 218-236.

Mathis, R., \& Jackson, J. (2006). Manajemen Sumber Daya Manusia. Edisi kesepuluh. Jakarta: Salemba Empat.

Mayo, A. (2000). The Role of Employee Development in The Growth of Intellectual Capital. Personal Review, 29(4), 129-141.

Mundia, C. N., \& Iravo, M. (2014). Role of Mentoring Programs on the Employee Performance in Organisations: A Survey of Public Universities in Nyeri County, Kenya. International Journal of Academic Research in Business and Social Sciences, 4(8), 393-412. https://doi.org/10.6007/ijarbss/v4-i8/1110

Neupane, R. (2015). Effects of Coaching and Mentoring on Employee Performance in the UK Hotel Industry. International Journal of Social Sciences and Management, 2(2), 123-138. https://doi.org/10.3126/ijssm.v2i2.12323

Ofobruku, S. A., \& Nwakoby, N. P. (2015). Effects of Mentoring on Employees' Performance in Selected Family Business in Abuja , Nigeria. Singaporean Journal of Business Economics and Management Studies, 4(9), 29-50. https://doi.org/10.12816/0019684

Oladimeji, M. S., \& Sowemimo, O. Z. (2020). The Effect of Mentoring on Employee Job Performance in the Nigerian Service Sector. Management of Organizations: Systematic Research, 84(1), 3144. https://doi.org/10.1515/mosr-2020-0011

Qosim, U., Seputra, A., \& Minarsih, M. M. (2020). Influence of The Work Environment, Motivation and Employee Competency on Employee Performance PT.Geo Given Visi Mandiri Semarang. Journal of Management, 6(1), 1-16. https://jurnal.unpand.ac.id/index.php/MS/article/view/1527

Rivai, V. (2009). Manajemen Sumber Daya Manusia Untuk Perusahaan: Dari Teori ke Praktek. Edisi ketiga. Depok: Rajawali Press. http://tibstrisakti.ac.id/files/Manajemen\%20Sumber\%20Daya\%20Manusia\%20Untuk\%20Perusahaan.pdf

Robbins, S., \& Decenzo, D. (2004). Fundamentals of Management. Edisi kedelapan. New Jersey: Prentice Hall. http://www.mim.ac.mw/books/Fundamentals\%20of\%20Management.pdf

Schuler, R., Dowling, P., Smart, J., \& Huber, V. (1992). Human Resource Management in Australia. Edisi kedua. Sydney: Harper Educational.

Setiawati, T., \& Ariani, D. (2019). The Influence of Fairness of Performance Appraisal and Job Satisfaction through Commitment on Job Performance. Review of Integrative Business and Economics Research, 9(3), 133-151.

Simmonds, A., \& Dick, A. (2018). Mentoring and Professional Identity Formation for Teaching Stream Faculty. International Journal of Mentoring and Coaching in Education, 7(4), 285-295.

Siswanto, B. (1996). Manajemen Sumber Daya Manusia. Edisi pertama. Jakarta: Galia.

Warokka, A., Gallato, C. G., \& Moorthy, T. (2012). Organizational Justice in Performance Appraisal System and Work Performance: Evidence from an Emerging Market. Journal of Human Resource Management Research, 2(1), 1-18

Wilandari, D. F., Sunarsi, D., \& Mas'adi, M. (2021). Pengaruh Penilaian Kerja Terhadap Kinerja Karyawan Pada PT. Jaya Mandiri Rekabuana di Cilandak. Jurnal Ekonomi Efektif, 3(2), 262- 
Moch. Bayu Hindarto. Pengaruh Penilaian dan Mentoring terhadap Peningkatan Kinerja Karyawan Rumah Sakit Islam Nasrul Ummah

269. https://doi.org/10.32493/jee.v3i2.8746

Tipung, D. D. (2018). Pengaruh Total Quality Management, Gaya Kepemimpinan, Kedisiplinan Kerja, dan Fungsi Mentoring Terhadap Kinerja Karyawan PT. Kemakmuran Berkah Timber Samarinda. Ekonomia,7(1),290-296.Diambildari smd.ac.id/index.php/EKM/article/view/3453 http://ejurnal.untag- 